Research Article

$\mathrm{J}$ Exp Clin Med

2021; 38(2): 187-191

doi: $10.52142 /$ omujecm.38.2.24

\title{
Retrospective clinical evaluation of patients undergoing surgery for acute epidural hematoma
}

\author{
Dursun TURKOZ ${ }^{\mathrm{a} *}$ (D) Cem DEMIREL ${ }^{\mathrm{a}}$ \\ ${ }^{1}$ Department of Neurosurgery, Faculty of Medicine, Health Sciences University, Samsun, Turkey
}

$\begin{array}{llll}\text { Received: } 15.12 .2020 & \bullet & \text { Accepted/Published Online: } 25.01 .2021 & \text { F }\end{array}$

\begin{abstract}
We aimed to evaluate mortality-associated factors among patients with acute epidural hematoma due to head trauma. Demographic characteristics, preoperative Glasgow Coma Scale score, epidural hematoma aetiology and radiological findings, accompanying systemic trauma results, hospitalisation duration, sequelae, and mortality features of patients experiencing epidural hematoma between 2014 and 2018 were evaluated. Overall, 79 patients were examined. The most frequent epidural hematoma aetiology was traffic accidents (51.9\%), with temporal region being the most common epidural hematoma location (38 [48.2\%] patients). Among all, 12 (15.2\%) patients died and 67 (84.8\%) were discharged. Of them, 57 (85.1\%) patients were discharged without and $10(14.9 \%)$ with neurological sequelae. Age $>65$ years $(\mathrm{p}=0.001)$ and low Glasgow Coma Scale score $(p<0.05)$ were significantly associated with higher mortality. Overall mortality rate was $91.7 \%(p<0.001)$ in patients with systemic trauma accompanying epidural hematoma, with thoracic $(12 \%)$ and orthopaedic $(9 \%)$ trauma being the most common. Cranial injuries included linear fracture, 78.5\%; pneumocephalus, 48.1\%; cerebral contusion, 44.3\%; traumatic subarachnoid haemorrhage, 32.9\%; acute subdural hematoma; $26.6 \%$, and collapse fracture, $15 \%$. All cranial injuries except linear fractures were associated with high mortality ( $\mathrm{p}<0.05)$. Epidural hematoma is associated with high mortality. Aetiology, Glasgow Coma Scale score, cranial pathology, age, and additional trauma are the major predictive mortality-associated factors.
\end{abstract}

Keywords: Epidural hematoma, Glasgow Coma Scale, head trauma, prognosis

\section{Introduction}

Traumatic brain injury (TBI) is a common cause of death and disability as well as one of the most important health and social problems in majority of the country including the United States. Every year millions of people in the United States suffer from TBI. Approximately 2.87 million TBI-related emergency department (ED) visits, hospitalizations and deaths occurred in the United States with over 837.000 of these events occurring among children (Araujo et al., 2012). Traumatic head injuries affect $2 \%$ of population and are a major cause of death among young people (Basamh et al., 2016).

Epidural hematomas (EDHs) occur in $0.2 \%-0.6 \%$ of all patients with head traumas (Bricolo and Pasut 1984; Bensard et al., 1994; Ceylan et al., 2013). Due to the thin squamous bone part and the anatomic localization of the anterior meningeal artery, skull fractures, especially those in the temporal bone, are more vulnerable to EDH development in patients with head traumas (Çırak et al., 1999). EDH develops as a rapidly expanding intracranial mass lesion and is, therefore, a true surgical emergency that typically requires immediate diagnosis and surgery (Çırak et al., 1999). Intriguingly, EDHs are four times more common in males than in females (Cooper et al., 1994).

Not many studies have investigated the incidence rate and social epidemiology of EDHs in Turkey. Reportedly, the majority of cases related to head trauma are a result of urbanization and industrialization not only in Turkey but also globally; traffic accidents, occupational crashes, falls and gunshot wounds are the most common causes of EDH (Eisenberg et al., 1990; Gulsen et al., 2015; Doan et al., 2016; Gurer et al., 2017). 
In this retrospective study, we examined factors associated with the prognosis of EDH. We also performed a review of the literature to contribute to the epidemiological database of Turkey.

\section{Material and method}

This retrospective cross-sectional study was approved by the ethics committee of University of Health Sciences (decision no: TUEK 174-2018 GOKAEK/11-82), Samsun Training and Research Hospital and was performed in accordance with the Declaration of Helsinki. This was a retrospective study of 79 patients who underwent surgery for acute EDH between January 2014 and November 2018 at the Neurosurgery Clinic of the Samsun Training \& Research Hospital, a primary hospital for treatment of trauma cases in the Black Sea region. Patients with acute EDH who did not undergo surgery were excluded from the study. Clinically stable patients were followed up in neurosurgery service and those patients were not included in the study.

Patient data included demographic data (age and sex), etiology, preoperative GCS score, radiological characteristics of hematoma, accompanying intracranial pathologies, additional systematic trauma symptoms, duration of hospitalization, sequelae, mortality and prognosis. The patients were divided into the following three clinical groups according to the GCS score based on the neurological examination conducted in the ED: severe, GCS score of $\leq 8$; moderate, GCS score of 9-12 and mild, GCS score of 13-15.

Data were collected for computed tomography (CT) findings for linear fractures, cerebral contusions, pneumocephalus and traumatic subarachnoid hemorrhage. Additionally, data were collected to investigate the association of multisystem injury with prognosis in patients with epidural hematoma length of hospitalization, sequelae and mortality.

\subsection{Statistical analysis}

Data were analyzed using SPSS 20.0 software. Continuous data were presented as mean \pm standard deviations, and quantitative data were expressed as numbers with percentages. Shapiro-Wilk test was used to assess the standard distribution of key parameters, Student's $t$ test was used to compare parametric data between two groups, and Mann-Whitney $U$ test was used for nonparametric comparison between groups.

\section{Results}

A total of 79 patients who underwent surgery for EDH were included in the final analysis. The mean patient age of the study cohort was $28.8 \pm 19.5$ years (range, $1-84$ years). There were $28(35.4 \%), 47(59.5 \%)$ and $4(5.1 \%)$ patients in the pediatric ( $\leq 18$ years), adult ( $18-65$ years) and elderly ( $\geq 65$ years) groups, respectively. There were $65(82.3 \%)$ males and 14 $(17.7 \%)$ females. The seasonal distribution of trauma revealed that $56 \%(n=45)$ of the traumas occurred between April and September.
The primary cause of EDH was trauma in the entire cohort. The two leading causes of trauma were falls (29 [36.7\%]) and traffic accidents (41 [51.9\%]), whereas assault (2 [2.5\%]), workplace accidents (6 [7.6\%]) and gunshot wounds (1 [1.3\%]) were rare causes of EDH. The patients in traffic accidents were further grouped into those inside and outside the vehicle. The rates of outside-vehicle and in-vehicle traffic accidents were $70.7 \%$ and $29.3 \%$, respectively. Further comparison of age groups revealed that traffic accidents were the most common etiology of EDH in all age groups. However, falls (42.9\%) were the second most common EDH etiology in the pediatric age group. Furthermore, the rate of falls was lower in the adult age group, and the rates of occupational accidents, assaults and gunshot wounds were higher in this age group (Table 1).

Table 1. Distribution of etiologies of epidural hematoma according to age groups

\begin{tabular}{|cccc|}
\hline Fall & $\begin{array}{c}\leq \mathbf{1 8} \text { years } \\
(\mathbf{n = 2 8})\end{array}$ & $\begin{array}{c}\mathbf{1 8 - 6 5} \text { years } \\
(\mathbf{n}=\mathbf{4 7})\end{array}$ & $\begin{array}{c}\mathbf{6 5} \text { years } \\
(\mathbf{n}=\mathbf{4})\end{array}$ \\
$\begin{array}{c}\text { Traffic } \\
\text { Accident }\end{array}$ & $15(52.9 \%)$ & $15(31.9 \%)$ & $2(50.0 \%)$ \\
$\begin{array}{c}\text { Assault } \\
\text { Occupational } \\
\text { Accident } \\
\text { Gun }\end{array}$ & $1(3.6 \% \%)$ & $24(51.1 \%)$ & $2(50.0 \%)$ \\
\hline
\end{tabular}

The GSC scores were minimum 4 and maximum 15 , respectively. The median GCS score was 12 . There were 29 (36.7\%), 28 (35.4\%) and 22 (28\%) patients in mild, moderate and severe clinical status, respectively, according to the GCS scores. The localizations of the EDH were parietal, temporal, frontal, occipital and temporoparietal in $13(16.5 \%), 38$ (48.2\%), 6 (\%7.6), $7(8.8 \%)$ and 15 (18.9\%) patients, respectively (Table 2).

Table 2. The localizations of the Epidural Hematoma (EDH)

\begin{tabular}{lcc}
\multicolumn{1}{c}{ Localization } & Number (n) & \% \\
\hline Parietal & 13 & 16.5 \\
Occipital & 7 & 8.8 \\
Temporal & 38 & 48.2 \\
Frontal & 6 & 7.6 \\
Temporoparietal & 15 & 18.9
\end{tabular}

Preoperative CT scans were taken to demonstrate other pathologies such as linear fractures, pneumocephalus and cerebral contusions in addition to the EDH in $62(78.5 \%)$ and $38(48.1 \%)$ and $35(44.3 \%)$ patients, respectively. Moreover, $26(32.9 \%)$ patients had traumatic subarachnoid hemorrhage and $12(15 \%)$ had compression fractures. Additionally, acute subdural hematomas occurred in $21(26.6 \%)$ of the patients. Multisystem trauma was present in $33(41.8 \%)$ patients. Among the accompanying pathologies, trauma to the thorax in $10(12 \%)$ patients and orthopedic trauma in $7(9 \%)$ patients were the two most frequent causes following head traumas.

Regarding outcomes, 12(15.2\%) patients died following 
the surgery, whereas $67(84.8 \%)$ patients were discharged. Among those, 57 (85.1\%) were without any sequelae, whereas $10(14.9 \%)$ patients had neurological sequelae. The mean hospitalization period was $14.84 \pm 20.67$ days, and the mean time to death was $6.81 \pm 7.34$ days. Specifically, the average length of hospitalization was $16.20 \pm 21.89$ days for the discharged patients.

Comparison of the GCS score with mortality revealed that the mortality of those with the lowest GCS scores was significantly higher than those of the other groups $(p<0.05)$ (Table 3). The mortality rates based on specific radiological findings are presented in Table 4. Briefly, preoperative radiological findings including pneumocephalus, cerebral contusions, traumatic subarachnoid hemorrhage and subdural hematoma were significantly associated with worse mortality after surgery for EDH. In contrast, there was no significant relationship between linear fractures and mortality.

Table 3. Mortality distribution according to Glasgow Coma Scale (GCS) scores $(\mathrm{p}<0.001)$

$\begin{array}{ccc}\text { GCS score } & \text { Deceased } & \text { Alive } \\ 3-8 & 12(57.1 \%) & 9(42.9 \%) \\ 9-12 & 0(0.0 \%) & 28(100.0 \%) \\ 13-15 & 0(0.0 \%) & 29(100.0 \%)\end{array}$

Table 4. Distribution of various concomitant pathologies in patients categorized according to outcomes

\begin{tabular}{|cccc|}
\hline & Deceased $(\mathbf{n}=\mathbf{1 2})$ & Alive $(\mathbf{n = 6 7 )}$ & $\mathbf{p}$ \\
\hline $\begin{array}{c}\text { Pneumocephal } \\
\text { us } \\
\text { Contusion }\end{array}$ & $11(91.7 \%)$ & $27(40.3 \%)$ & $<0.001$ \\
Subarachnoid & $12(100 \%)$ & $23(34.3 \%)$ & $<0.001$ \\
Subdural & $10(83.3 \%)$ & $16(23.9 \%)$ & $<0.001$ \\
$\begin{array}{c}\text { Linear } \\
\text { Fracture }\end{array}$ & $10(83.3 \%)$ & $11(16.4 \%)$ & $<0.001$ \\
$\begin{array}{c}\text { Other Trauma } \\
\text { Tran) }\end{array}$ & $11(91.7 \%)$ & $22(32.8 \%)$ & $<0.001$ \\
\hline
\end{tabular}

Mortality was observed in all of the $12(100 \%)$ patients who developed cerebral contusions $(\mathrm{p}<0.001)$. In addition, the mortality rates were $91.7 \%(n=11 ; p=0.001), 83.3 \%(n=10$; $\mathrm{p}=0.001), 83.3 \%(\mathrm{n}=10 ; \mathrm{p}=0.001)$ and $83.3 \%(\mathrm{n}=10 ; \mathrm{p}=$ 0.657) in those with pneumocephalus, subarachnoid hemorrhage, subdural hematoma and linear fractures, respectively (Table 4). The mortality rate was $91.7 \%(\mathrm{p}<$ 0.001 ) in patients with additional multisystem trauma. The analysis of mortality rates according to the cause revealed that the mortality rate was highest among those who underwent surgery for EDH following traffic accidents. On the other hand, $\mathrm{EDH}$ due to falls and assaults had the highest rate of discharge $(100 \%)$.

The mortality rates were $75 \%(\mathrm{p}=0.001), 17.65 \%$ and $3.6 \%$ in the elderly, adult and pediatric age groups, respectively. Evaluation of the patients for the duration of hospital stays revealed that the length of hospital stay (mean, $18.76 \pm 25.26$ days) was significantly longer in the adult age group than in the other two age groups $(\mathrm{p}=0.009)$.

\section{Discussion}

Preliminary diagnosis and effective intervention in highenergy head trauma are critically important for best outcomes with regard to mortality and morbidity. Acute EDH is a significant complication of head trauma. Those between the ages of 16 and 25 years are reportedly the most frequently affected by EDH due to head trauma (29.78\%) (Pandey et al., 2017). In the current study, the majority of patients with EDH due to head trauma were between the ages of 18 and $65(59.5 \%)$.

Pandey et al. (2017) reported that $88.29 \%$ of the 94 patients with bilateral traumatic intracranial hematoma were male. Similarly, a large study by Araujo et al. (2012) reported that $89.2 \%$ of the 210 patients who developed EDH due to trauma were male. Furthermore, in an extensive study, Sullivan et al. (1999) reported that $84 \%$ of the 252 epidural hematoma patients were male, whereas Tallon et al. (2008) found that $80 \%$ of the patients diagnosed with acute subdural and/or epidural hematoma due to head trauma were male. Gulsen et al. (2015) reported that $81.9 \%$ of the 226 patients who underwent surgery due to head injuries were male. The rate of $82.3 \%$ for males in the current study is in agreement with the previously published reports.

Araujo et al. (2012) concluded that the most frequent cause of trauma in EDH was falls (48\%), whereas in their study on childhood traumas, Cooper et al. (1994) reported that the causes were traffic accidents, falls, cycling accidents and others in $59 \%, 13 \%, 12 \%$ and $16 \%$ of the cases, respectively. Conversely, Bensard et al. (1994) evaluated the causes of trauma in children aged between 0 and 15 and reported that falls, traffic accidents, cycling accidents and others were the cause in $23 \%, 49 \%, 7 \%$ and $19 \%$ of the cases. Gürses et al. (2002) found that the rates of traffic accidents, falls and bicycle accidents as causes of trauma were $46 \%, 39 \%$ and $15 \%$, respectively. Simsek et al. (2005) extensively investigated the primary causes of pediatric head traumas and reported that traffic accidents, falls from a height, falls, cycling accidents and other causes were the etiology in $40.8 \%, 34.3 \%, 15.4 \%$, $5 \%$ and $14.5 \%$ of the cases, respectively. Conversely, Ceylan et al. (2013) reported that the most frequent cause of trauma was falling in $76.1 \%$ of the cases, whereas Çırak et al. (1999) found that traffic accidents were the primary cause of head trauma in $48 \%$ of the cases, followed by falls. Isik et al. (2011a) reported that the most frequent cause was traffic accidents at a rate of $75 \%$. In a study of 226 patients who underwent surgery for head trauma, Gulsen et al. (2015) found that the most common cause was falling in $51 \%$ of the patients, with traffic accidents constituting the second most common cause. Pandey et al. (2017) reported that the most common 
cause of head trauma was traffic accidents in $56.38 \%$ of their cohort. Gurer et al. (2017) recently reported that traffic accidents were the most common cause of trauma $(56.5 \%)$, with falling from a height in second place. In the current study, $51.9 \%$ of the patients experienced head trauma due to traffic accidents. Furthermore, the frequencies of traffic accidents and falls from a height were $53.6 \%$ and $42.9 \%$, respectively, in those under the age of 18 years.

In their study of their local ED, Ceylan et al. (2013) reported that $79.8 \%$ and $22.2 \%$ of the patients had mild and moderate/severe head trauma, respectively, based on the GCS scores. They also noted that none of the patients with moderate (GCS score, 10-13) and mild (GCS score, 14-15) head trauma died. Araujo et al. (2012) investigating 210 patients with EDH due to head trauma reported that $49 \%, 19 \%$ and $32 \%$ of the patients had mild (GCS score, 13-15), moderate (GCS score, 9-12) and severe (GCS score, 3-8), respectively (14). In the current study, our surveillance revealed that the rates of patients with EDH due to mild, moderate and severe head trauma were $26.6 \%, 35.4 \%$ and $36.7 \%$, respectively.

Kolodziej et al. (1999) reported that patients with GCS scores of 14 or above achieved significantly better results with conservative treatment. Kiymaz et al. (2001) found that six patients with neurologically and clinically good status who did not exhibit any focal signs with GCS scores of 14 and above recovered completely with conservative treatment. Bricolo et al. (1984) reported that the prognosis was better in patients with GCS scores between 8 and 15. These findings of previous studies are in agreement with the current study, where we evaluated the patients according to their GCS scores. Whereas the mortality rate of the patients with GCS scores between 3 and 8 was $57.1 \%$, there was no mortality cases in the groups with the GCS scores of 9-12 and 13-15. We also noted that the postoperative recovery was better in patients with high GCS scores. The evaluation of the patients who underwent surgery revealed that the median GCS scores of those who died and who survived following_surgery were 6 (4-12) and 12 (4-15), respectively; the difference was statistically significant $(\mathrm{p}<$ $0.001)$.

Araujo et al. (2012) reported that the primary location was the temporoparietal region in $26.5 \%$ of the patients. Bricolo et al. (1984) noted that the most common concomitant pathology in patients with acute EDH was linear fractures in the temporoparietal area. Importantly, in the current study, we also observed that EDH occurred in the temporal and temporoparietal areas in $53 \%$ of the patients and that the most common concomitant pathology was the temporoparietal linear fracture in $78.5 \%$ of the patients.

Our review of the literature did not identify any study investigating the correlation between radiological findings and mortality rates in patients with $\mathrm{EDH}$ due to head trauma. However, in the current study, we found that linear fractures were not associated with increased mortality but other consistent results influenced the death rates. Araujo et al. (2012) reported that the mortality rate was $15.5 \%$ among 210 patients with EDH due to trauma, whereas Bricolo et al. (1984) found that the mortality rate was $7 \%$ in their cohort of EDH patients. Similarly, Kiymaz et al. (26) showed that the mortality rate was $7 \%$ in their study. Gulsen et al. reported that the mortality rate was $23 \%$ in their cohort of patients who underwent surgery after head trauma and that the mortality rate of patients with EDH was 4.9\% (17). Lee et al. (28) commented that the time to reach the clinic and age were factors affecting prognosis in patients with acute EDH. In contrast, Kiymaz et al. (2001) found that the prognosis was dismal in all patients with GCS scores of 7 or less regardless of age or post-traumatic transport time. In the current study, the overall mortality rate was $15.2 \%$. In addition, the mortality rates were $3.6 \%, 17 \%$ and $75 \%$ in the pediatric, adult and elderly age groups, respectively, suggesting that increasing age was an adverse factor associated with higher mortality rate and reduced functional recovery. Furthermore, the mortality rate was higher at $22 \%$ in patients undergoing surgery for EDH due to traffic accidents compared to those with EDH due to other etiologies.

In the current study, $85.1 \%$ of the patients were discharged with full recovery and $14.9 \%$ of the patients who survived were discharged with sequelae. We did not evaluate the occurrence of trauma, arrival time to the hospital, or surgery time in our analyses as it was not clear. Isik et al. (2011b) conducted a retrospective analysis of 851 pediatric patients with head injuries and reported that although all patients included in the study experienced head trauma, all the traumas were not EDHs. Moreover, they reported that orthopedic and maxillofacial traumas were frequently noted. In the present study, thoracic and orthopedic trauma were the two most frequent causes of trauma not related with the head. Ceylan et al. (2013) reported that head trauma occurred most commonly in summer, especially in July and August. Isik et al. (2011b) found that the rate of trauma was highest in August and that the rate of patients who were hospitalized for head trauma from May to September comprised $60 \%$ of the study cohort. These findings are consistent with our findings.

Finally, gunshot wound-related trauma occurred only in one patient in the current study. The mortality of the series was given according to the discharge status of the patients and only short-term results are shared. This is the limitation of the study. Long term results are planned to be part of another study in the future.

This study aimed to determine the characteristics and outcomes of patients who were admitted to the EDH and underwent surgery revealed that EDH was associated with significant morbidity and mortality. Moreover, GCS at arrival, age, additional systemic trauma, certain etiologies and the presence of a cranial auxiliary pathology were important prognostic factors. The findings of the current study reveal that 
the majority of the deaths and disabilities caused by EDHs were due to preventable sources, highlighting the need for implementing appropriate measures to reduce mortality and morbidity.

\section{Conflict of Interest}

The authors declare that they have no competing interest.

\section{Acknowledgements}

We confirm that we read journal's position on issues involved in ethical publication and affirm that this report is consistent with those guidelines. This study was approved by decision no TUEK 174-2018 GOKAEK/11-82 by Samsun Training and Research Hospital ethical board members. The authors declare that this report does not contain any personal information that could lead to the identification of the patient(s) and/or volunteers.

\section{References}

1. Araujo, J.L., Aguiarudo, P., Todeschini, A.B., Saade, N., Veiga, J.C. 2012. Epidemiological analysis of 210 cases of surgically treated traumatic extradural hematoma. Rev. Col. Bras. Cir. 39(4), 268-271.

2. Basamh, M., Robert, A., Lamoureux, J., Saluja, R.S., Marcoux, J. 2016. Epidural hematoma treated conservatively: When to expect the worst. Can. J. Neurol. Sci. 43, 74-81.

3. Bensard, D.D., Mclntyre, R.C., Moore, E.E., Moore, F.A. 1994. A critical analysis of acutely injured children adult level I travma center. J. Pediatric. Surg. 29, 11-18.

4. Bricolo, A.P., Pasut, L.I. 1984. Extradural hematomas toward zero mortality. Neurosurgery. 14, 8-12.

5. Ceylan, D., Yaldız, C., Kızılcay, G., Gündüz, Y. 2013. Çocukluk çağı kafa travmaları: 357 olgunun retrospektif değerlendirilmesi. Türk Nöroşirürji Derg. 23, 255-260.

6. Çırak, B., Güven, M.B., Işı1k, S., Kıymaz, N., Demir, Ö. 1999. Acil servise başvuran travma hastaları ile ilgili epidemiyolojik bir çalışma. Ulus. Travma Derg. 51, 57-59.

7. Cooper, A., Barlow, B., DiScala, C., String, D. 1994. Mortality and truncal injury: Pediatric perspective. J. Pediatric Surg. 29, 33-38.

8. Doan, N., Patel, M., Doan, H., Janich, K., Nguyen, H.S., Shabani, S. 2016. Traumatic brain injury. Int. J. Phys. Med. Rehabil. 4, e120.

9. Eisenberg, H.M., GaryJr, H.E., Aldrich, E.F., Saydjari, C., Turner, B., Foulkes, M.A., Jane, J.A., Marmarou, A., Marshall, L.F., Young,
H.F. 1990. Initial CT findings in 753 patients with severe head injury. A report from the NIH Traumatic Coma Data Bank. J. Neurosurg. 73, 688-698.

10. Gulsen, I., Aycan, A., Arslan, M., Akyol, M.E. 2015. Sosuncu E Kafa travmasi nedeni ile ameliyat edilen 226 hastanın retrospektif değerlendirilmesi: Epidemiyolojik çalışma. Tıp Araş. Derg. 13, 128130.

11. Gurer, B., Kertmen, H., Yilmaz, E.R., Dolgun, H., Hasturk, A.E., Sekerci, Z. 2017. The surgical outcome of traumatic extra axial hematomas causing brain herniation. Turk. Neurosurg. 27, 37-52.

12. Gürses, D., Sarığlu, A., Başkan, M., Herek, Ö., Kılıç, İ. 2002. Travma nedeniyle çocuk acil servise başvuran hastaların epidemiyolojik değerlendirilmesi. Ulus. Travma Derg. 8, 156-159.

13. Işık, H.S., Bostanc1, U., Yıldız, Ö., Özdemir, C., Gökyar, A. 2011 a. Kafa travması nedeniyle tedavi edilen 954 erişkin olgunun retrospektif değerlendirilmesi. Ulus. Travma Acil Cerrahi Derg. 17, 46-50.

14. Iş̧1k, H.S., Gökyar, A., Yııldı,, O., Bostancı, U., Ozdemir, C. 2011 b. Çocukluk çağı kafa travmaları, 851 olgunun retrospektif değerlendirilmesi: Epidemiyolojik bir çalışma. Ulus. Travma Acil Cerrahi Derg. 17, 166-172.

15. Kıymaz, N., Demir, O., Yazıcı, T., Mumcu, Ç., Çırak, B. 2001. Akut epidural hematomlu hastalarda prognozu etkileyen faktörler. Van Tip Derg. 8, 117-119.

16. Kolodziej, W., Kiza, P., Podgorski, D., Czerwiński, K., Latka, D. 1999. Acute post traumatic epidural hematoma. Neurol. Neurochir. Pol. 33, 955-970.

17. Pandey, S., Sharma, V., Singh, K., Pandey, D., Sharma, M., Patil, D.B., Shende, N., Chauhan, R.S. 2017. Bilateral traumatic intracranial hematomas and its outcome: A retrospective study. Indian J. Surg. 79, 19-23.

18. Simşek, O., Hiçdönmez, T., Hamamcıŏlu, M.K., Kılınçer, C., Parsak, T., Tiryaki, M., Kurt, İ., Çobanoğlu, S. 2005. Pediatric head injuries: A retrospective analysis of 280 patients. Ulus. Travma Derg. 11, 310-317.

19. Sullivan, T.P., Jarvik, J.G., Cohen, W.A. 1999. Follow-up of conservatively managed epidural hematomas: Implications for timing of repeat CT. Am. J. Neuroradiol. 20, 107-113.

20. Tallon, J.M., Ackroyd-Stolarz, S., Karim, S.A., Clarke, D.B. 2008. The epidemiology of surgically treated acute subdural and epidural hematomas in patients with head injuries: a population-based study. Can J. Surg. 51, 339-345. 